\title{
Hexavalent molybdenum reduction to molybdenum blue by S. marcescens Strain Dr. Y6
}

\begin{abstract}
A molybdate-reducing bacterium has been locally isolated. The bacterium reduces molybdate or Mo(6+) to molybdenum blue (molybdate oxidation states of between 5+ and 6+). Different carbon sources such as acetate, formate, glycerol, citric acid, lactose, fructose, glucose, mannitol, tartarate, maltose, sucrose, and starch were used at an initial concentration of $0.2 \%$ (w/v) in low phosphate media to study their effect on the molybdate reduction efficiency of bacterium. All of the carbon sources supported cellular growth, but only sucrose, maltose, glucose, and glycerol (in decreasing order) supported molybdate reduction after $24 \mathrm{~h}$ of incubation. Optimum concentration of sucrose for molybdate reduction is $1.0 \%(\mathrm{w} / \mathrm{v})$ after 24 $\mathrm{h}$ of static incubation. Ammonium sulfate, ammonium chloride, valine, $\mathrm{OH}$-proline, glutamic acid, and alanine (in the order of decreasing efficiency) supported molybdate reduction with ammonium sulfate giving the highest amount of molybdenum blue after $24 \mathrm{~h}$ of incubation at $0.3 \%(\mathrm{w} / \mathrm{v})$. The optimum molybdate concentration that supports molybdate reduction is between 15 and $25 \mathrm{mM}$. Molybdate reduction is optimum at 35 degrees C. Phosphate at concentrations higher than $5 \mathrm{mM}$ strongly inhibits molybdate reduction. The molybdenum blue produced from cellular reduction exhibits a unique absorption spectrum with a maximum peak at $865 \mathrm{~nm}$ and a shoulder at $700 \mathrm{~nm}$. The isolate was tentatively identified as Serratia marcescens Strain Dr.Y6 based on carbon utilization profiles using Biolog GN plates and partial 16s rDNA molecular phylogeny.
\end{abstract}

Keyword: S. marcescens; Molybdate-reduction; Molybdenum blue 